\title{
Cryolipolysis: A Guide for Primary Care Practitioners
}

\author{
Miryam Harper \\ Brigham Young University - Provo \\ Jane H. Lassetter \\ Brigham Young University - Provo, jane_lassetter@byu.edu
}

Follow this and additional works at: https://scholarsarchive.byu.edu/facpub

Part of the Other Nursing Commons

\section{Original Publication Citation}

Harper, M., \& Lassetter, J. H. (2019). Cryolipolysis: A guide for primary care practitioners.

Journal for Nurse Practitioners, 15(9), 666-670.

\section{BYU ScholarsArchive Citation}

Harper, Miryam and Lassetter, Jane H., "Cryolipolysis: A Guide for Primary Care Practitioners" (2019). Faculty Publications. 5192.

https://scholarsarchive.byu.edu/facpub/5192

This Peer-Reviewed Article is brought to you for free and open access by BYU ScholarsArchive. It has been accepted for inclusion in Faculty Publications by an authorized administrator of BYU ScholarsArchive. For more information, please contact ellen_amatangelo@byu.edu. 


\title{
Cryolipolysis: A Guide for Primary Care Practitioners
}

\author{
Miryam Harper, MSN, RN, Jane Lassetter, PhD, RN
}

\author{
Keywords: \\ body contouring \\ body image \\ CoolSculpting \\ cryolipolysis \\ cryotherapy \\ fat
}

panniculitis

\begin{abstract}
A B S T R A C T
A desire for the ideal body image has influenced the development of a nonsurgical body-shaping procedure known as cryolipolysis. The purpose of this clinical feature is to inform nurse practitioners about the risks and benefits of cryolipolysis so they can educate their patients. Cryolipolysis is a safe, effective method of reducing small areas of unwanted fat. Adverse effects are minimal and include pain, redness, bruising, and swelling. Results are seen within 12 weeks, but long-term effects are unknown. There are contraindications, and it is relatively expensive; however, it may be a safer option than invasive surgery.
\end{abstract}

(C) 2019 Elsevier Inc. All rights reserved.

\section{Introduction}

Society's view of the ideal body image has changed throughout history. Before the 20th century, thinness was viewed as a representation of malnutrition, poverty, and disease, whereas heavier weight was associated with health, wealth, and prosperity. Artists during the Middle Ages depicted women with a heavier build, round stomachs, and large breasts and hips. This "reproductive figure" was considered superior for its ability to carry and bear healthy children. ${ }^{1(\mathrm{p} 18)}$

Since the 20th century, there has been an obsession with thinness, seemingly fueled by Hollywood and the fashion industry. In the 1920s, hand-drawn images of women with short hairstyles, flat chests, and shapeless figures were copied and distributed, causing women to bind their breasts, diet, and participate in extreme exercise routines to try and fit this mold. The 1940s brought a new influence from Hollywood, which emphasized curvy bodies and slim waists. Society idolized Marylyn Monroe, who demonstrated these qualities as a "pin-up girl" in the Playboy centerfolds. During the 1960 s to 1990 s, women wanted to be very thin, as depicted by the fashion model "Twiggy" and actress Audrey Hepburn, both of whom were tall and slender, with an almost emaciated look. Still influenced by Hollywood, photo-shopped images, and social media, today's women want to be slim but muscular with large breasts and bottom and a flat stomach. ${ }^{1}$ Men, throughout time, have idolized the athletic, muscular build that is depicted in the marble sculptures of ancient days. ${ }^{1}$ To obtain these ideal body shapes, men and women have turned to gym memberships, nutritional regimens, and cosmetic procedures.

To meet their ideal body goal, Americans are trending toward nonsurgical cosmetic interventions, where applicable, instead of surgical interventions. In 2016, the American Society for Aesthetic Plastic Surgery reported 627,243 Americans had surgery (liposuction, male breast reduction, abdominoplasty) and 169,695 had a nonsurgical procedure (CoolSculpting [ZELTIQ Aesthetics, Inc.,
Pleasanton, CA]/cryolipolysis, Vaser Shape [Sound Surgical Technologies LLC, Louisville, CO], Liposonix [Valeant Pharmaceuticals International, Inc., Hayward, CA) to remove unwanted fat. Although more people had surgical rather than nonsurgical procedures, the increase in nonsurgical procedures compared with 2015 was 5.6\% and in surgical procedures was $2.7 \% .^{2}$ Thus, nonsurgical procedures are gaining in popularity.

Liposuction has traditionally been the gold standard for removing excessive adipose tissue, but because of the common surgical risks of infection, pain, scarring, bruising, thrombosis, and risks associated with anesthesia, it may not appeal to some populations. $^{2}$ The growing number of men and women having nonsurgical procedures indicates that people are seeking less invasive body-shaping procedures.

The cost difference and recovery time may also be a reason people are choosing the nonsurgical approach. In 2017, the average abdominoplasty treatment was $\$ 6,083$ with 2 to 4 weeks of recovery. In contrast, the 3 currently available nonsurgical, fat reduction procedures averaged $\$ 1,664$, with little or no downtime. ${ }^{3}$

Advertisements for cryolipolysis, a widely marketed, noninvasive fat reduction procedure, pique the interest of men and women with a desire to achieve their ideal body image. They then turn to their primary care providers for advice, asking:

- How does it work?

- Does it work long-term?

- Where and how is it performed?

- How does it compare to other body-sculpting procedures?

- Is it affordable?

- Is it safe?

- Am I a candidate?

Providers should be able to inform their clients with a basic knowledge of the procedure as well as the associated risks and benefits. The purpose of this clinical feature is to provide nurse 
practitioners (NPs) and other care providers with current evidence regarding the risks, benefits, and realities of cryolipolysis or CoolSculpting so they can educate their patients.

\section{Background}

Historically, cryolipolysis developed after observing inflammation and atrophy of adipose tissue, or panniculitis, in the mouths of children after cold exposure from eating frozen popsicles. This same phenomenon was also observed in the thighs of women who rode horseback in cold weather. This phenomenon inspired Manstein et $\mathrm{al}^{4}$ to further investigate the theory of adipocyte inflammation and reduction by localized cold exposure to the abdomens of pigs. They found a significant reduction in exposed adipocytes that continued 3.5 months after cold exposure. Another significant finding was the lack of damage to exposed skin and surrounding tissues. This study was the pioneer to other investigations of the use of localized cold to spot reduce unwanted fat. ${ }^{4}$

\section{How Does Cryolipolysis Work?}

Cryolipolysis induces selective apoptosis to adipocytes, which are then carried away by the inflammatory process. There is no change to the cells and tissue immediately after a treatment, but within 3 days, evidence is seen of adipocyte apoptosis and initiation of an inflammatory response with an increase of inflammatory cells. The exact mechanism that sparks this apoptosis is still unknown. Inflammation peaks 14 days after treatment as macrophages, neutrophils, and lymphocytes surround the adipocytes. At approximately 30 days after treatment, the adipocytes appear smaller and are irregularly shaped as they are taken up through phagocytosis. Inflammation declines after 90 days, and the thickness of the fat layer when observed microscopically is visibly reduced. ${ }^{5}$

\section{Is Cryolipolysis Effective?}

The United States Food and Drug Administration (FDA) approved ZELTIQ's CoolSculpting device for cryolipolysis use in 2010, stating "The CoolSculpting System is indicated for coldassisted lipolysis (breakdown of fat) of the sub-mental area, thigh, abdomen, and flank, or 'love handles' in individuals with a Body Mass Index (BMI) of 30 or less. The device is intended to affect the appearance of visible fat bulges in the sub-mental area, thigh, abdomen and flank." 6

A few large studies have evaluated the evidence regarding the effectiveness of cryolipolysis. In 2013, Stevens et $\mathrm{al}^{7}$ reviewed the medical records of 528 patients 18 to 79 years old who underwent cryolipolysis (CoolSculpting). They compared the number of treatments each patient received, areas treated, and any reported complications. Each patient was photographed and then received a treatment lasting 60 minutes. Then, if indicated, a second treatment was given 8 weeks later. The most common treatment sites were the lower abdomen and bilateral flanks. Only 3 patients reported complications of pain or neuralgia, which resolved within 4 days.

Follow-up visits involved posttreatment photographs to compare treatment results against the baseline photographs and a patient satisfaction survey. Only 4 of the 528 patients were dissatisfied enough to ask for a refund. However, those 4 all expressed satisfaction after a free supplemental treatment. ${ }^{7}$ Limitations of this study included that it was a retrospective medical record review and that ZELTIQ the CoolSculpting device manufacturer, provided some funding for the study. Further, results were based on patient satisfaction and did not include any actual measurements.

Another large study conducted in Europe evaluated 518 participants with healthy body mass index values but localized fat deposits. Researchers examined safety, tolerance, and satisfaction after a cryolipolysis (CoolSculpting) procedure. They compared the number of treatments, areas treated, and adverse effects immediately after treatments. Three months after treatment, participants completed a satisfaction survey, were photographed, and measured with calipers.

Results indicate most of the participants chose to treat flanks (59\%) and abdomen (28\%), and most underwent only 1 treatment. Reported short-term adverse effects were erythema (100\%), minimal pain (96\%), bruising (9.8\%), severe pain with application of the device (4\%), changes in sensitivity $(2.9 \%)$, and vasovagal response (2.1\%). All of these adverse events resolved spontaneously within a few days.

After 3 months, caliper measurements averaged 23\% fat reduction in $94 \%$ of the participants, $73 \%$ were satisfied or extremely satisfied with their results, and $82 \%$ would recommend cryolipolysis to a friend. In the photographic comparison, $85.5 \%$ of participants showed visible reduction in the size of the abdomen or flank but little or no visible reduction on treated thighs, knees, and buttocks. No discoloration was reported. Limitations of this study included that $56 \%$ of participants could not be contacted for followup evaluation. ${ }^{8}$

A recent study conducted in France used one of several other marketed cryolipolysis devices (CRISTAL Cryolipolysis; ICE AESTHETIC GmbH, Berlin, Germany). There were 147 patients who underwent 60 minutes of cold exposure to either flank, abdomen, thigh, back, or buttocks, followed by 5 minutes of massage to the treated area. Reported adverse effects included severe pain $(0.6 \%)$, vasovagal response (2\%), numbness $(0.6 \%)$, bruising $(1.3 \%)$, erythema/blistering $(0.6 \%)$, and painful induration at site of treatment (2.7\%). All adverse events resolved independently, and there was no report of paradoxical adipose hyperplasia (PAH), a reaction in which tissue at the treatment site enlarges rather than reduces. The mean circumference loss for all treatment sites was $2.8 \mathrm{~cm}(P<.05)$. Of the 147 participants treated, $75.5 \%$ were satisfied with their results, and $80.6 \%$ expressed interest in receiving a second treatment. $^{9}$

These 3 studies all indicate high participant satisfaction, measurable results, and a few temporary adverse effects that resolved without intervention. There are some limitations to consider. Standardizing measurement techniques is difficult due to variables such as the pressure applied to the calipers or ultrasound probe when measuring tissue thickness. However, the large sample size in these studies helps support the results despite these limitations.

\section{Does Cryolipolysis Last Long-Term?}

Cryolipolysis was first approved by the FDA in 2010, so it is still quite new. Thus, little research has been conducted on the longterm effectiveness. A study completed in 2016 evaluated the effectiveness of cryolipolysis in 2 male participants over a period of 6 and 9 years. The first participant, who was 44 years old at the time of treatment, received two 60-minute cycles to his left flank. The right side remained untreated as a control comparison. Photographs of his flanks were taken at baseline, 2 months, 2 years, and 6 years. Compared with baseline, this man gained 10 pounds at 2 years and 5.2 pounds at 6 years. The second participant, who was 45 years old at time of treatment, received one 60-minute treatment to his right flank. The left remained untreated as a control. Photographs of his flanks were taken at baseline, 3 months, 5 years, 
and 9 years. Weight from baseline fluctuated from a 10-pound decrease at 5 years to a 0.2 -pound decrease at 9 years. At the conclusion of the study, physicians certified in dermatology or plastic surgery blindly evaluated the progressive photographs of both participants. They were able to distinguish the baseline from posttreatment photographs $100 \%$ of the time by comparing flank size. $^{10}$

Although the sample size of this study was small and limited to only male participants who had only one area treated, it indicates that there is potential for long-term effectiveness of cryolipolysis despite weight changes. As the popularity of cryolipolysis increases, more studies are needed evaluating the long-term results of various treatment sites on a variety of people.

\section{How is Cryolipolysis Performed?}

After an initial consultation with a trained provider, cryolipolysis is done using a vacuum cupped applicator attached to the treatment site. An aesthetician or health care provider applies a gel layer to the skin before placing the applicator. This ensures equal thermal contact between the machine and the tissue being treated. The tissue is cooled to a temperature just above freezing and is maintained at that temperature for 40 to 60 minutes. During this time, no intervention is needed. When the treatment is almost over, the machine notifies the operator to remove the applicator. The site is then massaged for approximately 5 minutes, and the client is sent home. Depending on the treatment site, a second treatment may be done about 8 weeks after the first. Results are often seen within approximately 3 weeks and peak by about 12 weeks. ${ }^{4}$

\section{Where is Cryolipolysis Performed?}

Cryolipolysis is performed at a variety of locations, including medical spas, plastic surgeons' offices, dermatology clinics, family practice clinics, and beauty salons. The procedure is done by someone trained to use the machine, which includes medical assistants, aestheticians, nurses, physician assistants, NPs, and physicians. It should always be done under the supervision of a board-certified licensed provider who has undergone the recommended training in order to consult, advise, perform the procedure, and follow-up. ZELTIQ Aesthetics, the manufacturer of CoolSculpting, the only FDA-approved cryolipolysis device, offers a 3-day training to individuals who operate their machines. ${ }^{11}$ Consumers should be wary of providers who lack proper certification.

\section{How Does Cryolipolysis Compare to Other Procedures?}

There are risks associated with undergoing a major surgical procedure, including pain, infection, scarring, deep vein thrombosis, pulmonary embolism, prolonged recovery time, and anesthesia-associated complications. Surgical procedures can also be very expensive when combined with hospital and anesthesia bills. The risks and expense of surgery is likely to dissuade many candidates from undergoing elective body-shaping procedures, especially since less risky nonsurgical options are now available.

Cryolipolysis may be the answer for people who have small amounts of unwanted fatty tissue in localized areas. It causes minimal pain, carries no infection risk, requires little to no downtime, and can be done in an office or clinical setting without anesthesia, which reduces the cost. Another benefit to cryolipolysis is that it does not affect systemic lipid levels or liver enzymes, which would allow patients with conflicting comorbidities (see below), who would not be surgical candidates, to participate. ${ }^{12}$

How does cryolipolysis compare to other nonsurgical fat reduction procedures? In an 8 -week randomized controlled trial comparing cryolipolysis to diet and laser lipolysis therapy (an FDAapproved method of removing unwanted fatty tissue), cryolipolysis had the greatest fat layer reduction using caliper skinfold measurements on obese adolescents. ${ }^{13}$ Kennedy et al ${ }^{14}$ compared 4 nonsurgical treatments: cryolipolysis, low-level laser therapy, radiofrequency, and high-intensity focused ultrasound, along with a few additional techniques such as mechanical massage, shockwave therapy, acoustic wave therapy, and topical creams. The researchers found the initial 4 treatments were all effective but noted that the greatest reduction occurred when cryolipolysis was combined with shockwave therapy (a technique used to reduce cellulite). ${ }^{14}$

As more people are self-reporting their results and satisfaction with body sculpting procedures on social media outlets, one group of researchers collected real-world data from this resource. They found that surgical liposuction had higher patient satisfaction scores (66\%) than nonsurgical procedures (58\%). Consumers should be aware that social media has several limitations and does not take into account various aspects such as a patient's medical history, body mass index, or the provider's background and ability. ${ }^{15}$

\section{What are the Adverse Effects of Cryolipolysis?}

The process of freezing localized adipocytes to induce apoptosis and removal by the inflammatory response has some imperfections. As observed in the European study done in 2013, 100\% of patients reported erythema at the site, and 96\% reported minimal pain. There are also reports of bruising, numbness, blistering, severe pain, and syncope. These adverse reactions are reported to be short-lived, resolving within a few days. ${ }^{8}$ One study reported that $15 \%$ of patients experience severe delayed postcryolipolysis pain after day 3. Those most at risk are young women (mean age, 39) who elect for abdominal cryolipolysis. These patients may be managed with nonsteroidal anti-inflammatory drugs, a short course ( 2 weeks) of low-dose gabapentin, lidocaine patches, or acetaminophen. Most patients do not require any intervention after 11 days. ${ }^{16}$

\section{What are the Contraindications for Cryolipolysis?}

Although the option of cryolipolysis is available to more people than an invasive surgical procedure would be, there are still a few conditions that would prevent an individual from being a candidate. Because the immune system eliminates the adipocytes, anyone who is immunocompromised would not be a candidate. It should not be used as a treatment for obesity because it only removes localized fat deposits. Circulatory contraindications include Raynaud disease, use of blood thinners, hypocoagulability, and cryoglobulinemia, a disorder with increased risk for blockages in the vasculature when exposed to cold. The skin at or near a treatment site should be carefully assessed to determine that it is healthy and appropriate for treatment. Caution should be used in treating anyone with eczema, psoriasis, dermatitis, hives, scar tissue, recent injury, or cellulitis at or near the desired treatment site. Individuals who are pregnant or breastfeeding, suffer from chronic pain or severe anxiety, or who have a hernia or implanted device near the treatment site should also reconsider the option of cryolipolysis. $^{17}$

\section{What are the Risks of Cryolipolysis?}

Only a few long-term risks are associated with cryolipolysis. The most commonly reported risk is a phenomenon called PAH, which is a well-demarcated area of tissue enlargement at the site of treatment after cryolipolysis. It is rare, occurring at a rate of 
Table

Pros and Cons of Cryolipolysis

\begin{tabular}{|c|c|}
\hline Pros & Cons \\
\hline $\begin{array}{l}\text { Works well for small stubborn areas that are difficult to reduce through } \\
\text { diet and exercise }\end{array}$ & Not for large area reduction and not a weight loss solution \\
\hline Results appears to maintain over several years, despite mild weight gain & Results take up to 3 months for completion \\
\hline May be done as an outpatient in a certified clinic, spa, or beauty salon & May require multiple treatments \\
\hline Adverse effects are temporary, usually resolving within 3 days & $\begin{array}{l}\text { Side effects include immediate } \\
\text { - Pain } \\
\text { - Erythema } \\
\text { - Bruising } \\
\text { - Numbness }\end{array}$ \\
\hline Long-term risks are rare and can be prevented under most circumstances & $\begin{array}{l}\text { Long-term risks include } \\
\text { - Paradoxical adipose hyperplasia } \\
\text { - Frostbite }\end{array}$ \\
\hline Less expensive than surgical cosmetic procedures & $\begin{array}{l}\text { Third most expensive nonsurgical cosmetic procedure in the United States } \\
\text { (\$1,664 average cost of treatment in } 2017)\end{array}$ \\
\hline Fewer contraindications than for surgical procedures & Contraindications exist \\
\hline
\end{tabular}

$0.0051 \%{ }^{18}$; however, this may have been underreported. One clinic in Miami reported a $0.78 \%$ occurrence rate in 510 patients treated. This clinic observed that PAH occurred more often in Hispanic men in whom the lower abdomen was treated with a single applicator. There may be a genetic predisposition for developing PAH because it occurred in twins treated at different clinics. ${ }^{19}$ When PAH is suspected, no further cryolipolysis treatments should be performed, and the patient should be treated with surgical liposuction to remove the enlarged adipocytes. ${ }^{20}$

A second long-term risk of cryolipolysis is frostbite at the treatment site. One case report describes a 35-year-old woman who underwent a single 60-minute treatment on her flanks in an uncertified beauty salon. She reported pain with rewarming and blisters at the site a few hours after the treatment. This subsequently resulted in necrotic tissue requiring 6 weeks of careful treatment and observation by a plastic surgeon. This case emphasizes the importance of choosing a certified provider with positive reported outcomes. ${ }^{21}$ A second case occurred when a 55-year-old woman attempted a do-it-yourself cryolipolysis treatment at home using dry ice. This resulted in full- and partial-thickness burns to $4 \%$ total body surface area on her abdomen, which required skin grafting. Providers should be aware that there are online sources describing how to perform cryolipolysis at home. These attempts should be discouraged due to the inability to monitor and maintain a constant treatment temperature without the use of a certified cryolipolysis device. ${ }^{22}$

\section{How Much Does Cryolipolysis Cost?}

As mentioned previously, when comparing nonsurgical to surgical fat reduction procedures, cryolipolysis is less expensive due to its noninvasive nature and can be done in an outpatient setting without anesthesia or other modalities. However, this does not mean that it is inexpensive. In 2017, the average cost of a nonsurgical fat reducing procedure (CoolSculpting, Vaser Shape, Liposonix) was $\$ 1,664$. Often a patient undergoes 2 or even 3 cryolipolysis treatments, which would double or triple that expense per treatment site. Although less expensive than a surgical procedure, cryolipolysis is the third most expensive nonsurgical cosmetic procedure in the United States. ${ }^{3}$

A large portion of the payment for a CoolSculpting (cryolipolysis) procedure covers overhead costs. The provider who purchases a machine must also purchase cards that allow the machine to run. One card allows 16 to 24 cycles. Without a card, the machine will not work, enabling ZELTIQ (the manufacturer of the machines) to continue earning revenue on machines after they are sold. $^{23}$

\section{Role of the NP in Regard to Cryolipolysis}

An NP may play a few different roles in the process of cryolipolysis, such as teaching, screening, consulting, or performing the actual procedure. The information in this report is intended for NPs or other health care providers with patients who request information about cryolipolysis and have questions about its physiology, efficacy, long-term benefits, how and where it is performed, how it compares to other procedures, the risks and benefits, whether they are a candidate, and whether it is affordable. The Table provides guidance in teaching patients about cryolipolysis treatment.

\section{Conclusion}

As society today is drawn toward an ideal body shape, NPs and other health care providers need to be aware of the options that are available to their patients and be able to educate them with unbiased information. Cryolipolysis appears to be a safe, effective, nonsurgical procedure that allows limited removal of adipocytes from troublesome areas. There are many factors to consider regarding each individual's health, but with the information in this clinical report, an NP or other health care provider is better equipped in guiding a patient who is considering cryolipolysis as a body-shaping option.

\section{References}

1. Grogan S. Body Image: Understanding body dissatisfaction in men, women and children. 3rd ed. New York, NY: Routledge; 2017.

2. Friedmann D. A review of the aesthetic treatment of abdominal subcutaneous adipose tissue: background, implications, and therapeutic options. Dermatol Surg. 2015;41(1):18-34. https://doi.org/10.1097/DSS.0000000000000209.

3. The American Society for Aesthetic Plastic Surgery. Cosmetic Surgery National Data Bank Statistics. https://www.surgery.org/sites/default/files/ASAPSStats2017.pdf. Published 2017. Accessed March 10, 2019.

4. Manstein D, Laubach H, Watanabe K, Farinelli W, Zurakowski D, Anderson R. Selective cryolysis: a novel method of non-invasive fat removal. Lasers Surg Med. 2008;40(9):595-604. https://doi.org/10.1002/Ism.20719.

5. Avram M, Harry R. Cryolipolysis for subcutaneous fat layer reduction. Lasers Surg Med. 2009;41(10):703-708. https://doi.org/10.1002/1sm.20864.

6. Department of Health and Human Services. Food and Drug Administration. Zeltiq Aesthetics, Inc. 510(K) CoolSculpting System. https:// www.accessdata.fda.gov/cdrh_docs/pdf16/K162050.pdf. September 2015. Accessed June 2, 2019.

7. Stevens W, Pietrzak L, Spring M. Broad overview of a clinical and commercial experience with CoolSculpting. Aesthet Surg J. 2013;33(6):835-846. https:// doi.org/10.1177/1090820X13494757.

8. Dierickx C, Mazer J, Sand M, Koenig S, Arigon V. Safety, tolerance, and patient satisfaction with noninvasive cryolipolysis. Dermatol Surg. 2013;39(8): 1209-1216. https://doi.org/10.1111/dsu.12238. 
9. Naouri M. Fat removal using a new cryolipolysis device: a retrospective study of 418 procedures. J Eur Acad Dermatol Venereol. 2017;31(3):e158-e160. https://doi.org/10.1111/jdv.13899.

10. Bernstein E. Long-term efficacy follow-up on two cryolipolysis case studies: 6 and 9 years post-treatment. J Cosmet Dermatol. 2016;15(4):561-564. https:// doi.org/10.1111/jocd.12238.

11. Allergan Ltd. Coolsculpting Programs and training. http://coolsculptinghcp.com/ practice/training-programs/. Published April 2018. Accessed March 7, 2019.

12. Klein K, Bachelor E, Becker E, Bowes L. Multiple same day cryolipolysis treatments for the reduction of subcutaneous fat are safe and do not affect serum lipid levels or liver function tests. Lasers Surg Med. 2017;49(7):640-644. https://doi.org/10.1002/lsm.22674.

13. Mostafa M, Elshafey M. Cryolipolysis versus laser lipolysis on adolescent abdominal adiposity. Lasers Surg Med. 2016;48(4):365-370. https://doi.org/ $10.1002 / 1 \mathrm{sm} .22475$.

14. Kennedy J, Verne S, Griffith R, Falto-Aizpurua L, Nouri K. Non-invasive subcutaneous fat reduction: a review. J Eur Acad Dermatol Venereol. 2015;29(9): 1679-1688. https://doi.org/10.1111/jdv.12994.

15. Talasila S, Evers-Meltzer R, Xu S. Social media ratings of minimally invasive fat reduction procedures. Dermatol Surg. 2018;44(7):971-975. https://doi.org/ 10.1097/DSS.0000000000001509.

16. Keaney T, Gudas A, Alster T. Delayed onset pain associated with cryolipolysis treatment: a retrospective study with treatment recommendations. Dermatol Surg. 2015;41(11):1296-1299. https://doi.org/10.1097/DSS.00000 00000000502.

17. Huizen J. What are the risks of CoolSculpting? Medical News Today. https:// www.medicalnewstoday.com/articles/320138.php. Published November 25, 2017. Accessed March 7, 2019.
18. Jalian H, Avram M, Garibyan L, Mihm M, Anderson R. Paradoxical adipose hyperplasia after cryolipolysis. JAMA Dermatol. 2014;150(3):317-319. https:// doi.org/10.1001/jamadermat01.2013.8071.

19. Kelly E, Rodriguez-Feliz J, Kelly M. Paradoxical adipose hyperplasia after cryolipolysis: a report on incidence and common factors identified in 510 patients. Plast Reconstr Surg. 2016;137(3):639e-640e. https://doi.org/10.1097/ 01.prs.0000480023.35573.b7.

20. Seaman S, Tannan S, Cao Y, Peirce S, Gampper T. Paradoxical adipose hyperplasia and cellular effects after cryolipolysis: a case report. Aesthet Surg J. 2016;36(1):NP6-NP13. https://doi.org/10.1093/asj/sjv105.

21. Choong W, Wohlgemut $\mathrm{H}$, Hallam M. Frostbite following cryolipolysis treatment in a beauty salon: a case study. J Wound Care. 2017;26(4):188-190. https://doi.org/10.12968/jowc.2017.26.4.188.

22. Leonard C, Kahn S, Summitt J. Full-thickness wounds resulting from 'do-ityourself cryolipolysis: a case study. J Wound Care. 2016;25(Sup4):S30-S32. https://doi.org/10.12968/jowc.2016.25.Sup4.S30.

23. International Association for Physicians in Aesthetic Medicine. The Cold Hard Truth About CoolSculpting ${ }^{\circledR}$. https://iapam.com/cold-hard-truth-cool sculpting.html. Accessed March 7, 2019.

Both authors are affiliated with at Brigham Young University College of Nursing, Provo, UT. Miryam Harper, MSN, RN, is a family nurse practitioner student and can be contacted at miryam.millie@gmail.com. Jane Lassetter, PhD, RN, is professor and associate dean of graduate studies.

In compliance with national ethical guidelines, the authors report no relationships with business or industry that would pose a conflict of interest. 